\title{
Metaphilosophy and Argument: The Case of the Justification of Abduction
}

\author{
Paula Olmos
}

\author{
Department of Linguistics, Modern Languages, Logic and Philosophy of \\ Science, Theory of literature and comparative literature. \\ Universidad Autónoma de Madrid \\ Avda. Francisco Tomás y Valiente, 1. 28049 Madrid \\ Spainpaula.olmos@uam.es
}

\begin{abstract}
This paper is an essay on metaphilosophy that reviews, describes, categorises, and discusses different ways philosophers have approached the justification of abduction as a mode of reasoning and arguing. Advocating an argumentative approach to abduction, I model the philosophical debate over its justification as the critical assessment of a warrant-establishing argument allowing " $\mathrm{H}$ explains D" to be used as a reason for "H can be inferred from D." Philosophers have discussed the conditions under which such kind of generic argument can be accepted, and I identify five kinds of such conditions, namely: a) dialectical/procedural restriction; b) claim restriction; c) restriction over acceptable explanatory principles; d) balancing restriction; and e) epistemic restriction.
\end{abstract}

Résumé: Cet article est un essai sur la métaphilosophie qui passe en revue, décrit, catégorise et discute des différentes manières dont les philosophes ont abordé la justification de l'abduction en tant que mode de raisonnement et d'argumentation. Préconisant une approche argumentative de l'abduction, je modélise le débat philosophique sur sa justification comme l'évaluation critique d'un argument établissant une loi de passage permettant d'utiliser « $\mathrm{H}$ explique $\mathrm{D} »$ comme raison pour $« \mathrm{H}$ peut être déduit de $\mathrm{D} »$. Les philosophes ont discuté des conditions dans lesquelles un tel type d'argument générique peut être accepté et j'identifie cinq types de telles conditions, à savoir : a) restriction dialectique/ procédurale ; b) la restriction des énoncés ; c) restriction des principes explicatifs acceptables; d) restriction d'équilibrage et e) restriction épistémique.

Keywords: abduction, explanation, inference to the best explanation, justification, metaphilosophy, Toulmin's model, warrant. 


\section{Introduction: Philosophy as a case-making activity}

This paper is an essay on metaphilosophy in as much as it tries to review, describe, categorise and discuss different ways philosophers have approached a certain self-assumed philosophical task. In our case, this task is the justification of a certain mode of reasoning and arguing, namely abduction. Such an endeavour responds to a tradition that has been mainly represented by the wellknown and long-standing philosophical discussion about the "justification of induction."Our inquiry is, in any case, presided over by the assumption that what philosophers mainly do is argue. So the idea is to approach their pursuit as an argumentative activity and, more specifically, under a conception of arguing and argument that does not aim to capture what follows from what, of what is implied by what, but tries instead to understand how something (some content) is presented/proposed by someone to others as a reason for something else in a communicative setting (Marraud 2013).

This idea of philosophy, not only as an argumentative activity but, more specifically, as a kind of case-making activity under the model of legal discussion, was already proposed by Friedrich Waismann in his definitely metaphilosophical and influential paper "How I See Philosophy" (1968 [1956]).

The essential difference between philosophy and logic is that logic constrains us while philosophy leaves us free: in a philosophic discussion we are led, step by step, to change our angle of vision $[\ldots]$ a thing profoundly different from deducing theorems from a given set of premisses (Waismann 1968 [1956], p. 21)

[philosophical arguments] were, quite mistakenly as I hope to have shown, supposed to be proofs and refutations in a strict sense. But what the philosopher does is something else. He builds up a case. First, he makes you see all the weaknesses, disadvantages, shortcomings of a position; he brings to light inconsistencies in it or points out how unnatural some of the ideas underlying the whole theory are by pushing them to their farthest consequences $[\ldots]$ On the other hand, he offers you a new way of looking at things not exposed to those objections. In other words, he submits to you, like a barrister, all the facts of his case, and you are in the position of a judge (Waismann 1968 [1956], p. 30). 
But one interesting twist is that philosophy is a case-making or reason-giving activity that is particularly interested in other casemaking or reason-giving activities: from the most ordinary, domestic ones learned through the very process of language acquisition, to the most sophisticated and heavily institutionalized ones learned through specific training. Jonathan L. Cohen even characterizes philosophy as "the reasoned investigation of reasons" or "the reasoned discussion of what can be a reason for what" (Cohen 1986, pp. 49-50, 57). This last remark fits exactly the discussion about the "justification of abduction" in just the way we are going to reconstruct it here.

On the other hand, it should not be overlooked that, precisely in our case, the philosophical interest in the justification of abduction has been particularly encouraged by its centrality for other philosophical discussions, such as those regarding science and its own methods within philosophy of science (Olmos 2018a). Although John Woods's paper on the logic of abduction (2017) aims at a more general, epistemological picture of what, according to his view, is basically a naturalistic and evolutionarily developed mode of reasoning, he must nevertheless deal with the nature of scientific enquiry and its own justificatory standards. It is in this particular regard that he offers us a usefully argumentative characterization of science itself, another forensic (publicly exposed), casemaking (communicative, reason-giving) activity:

Not unlike the law, science is in significant measure a casemaking profession -a forensic profession- made so by the premium it places on demonstrating that knowledge has been achieved, rather than just achieving it. This has something to do with its status as a profession, subject to its own exacting requirements for apprenticeship, standard practice, and advancement. These are factors that impose on people in the showing professions expectations that regulate public announcement. [...] Publication is a vehicle for case-making, and case-making is harder than knowing. Journal editors don't give a toss for what you know. But they might sit up and notice if you can show what you know (Woods 2017 pp. 143-144).

So the philosophical justification of abduction deserves a doubly argumentative approach, as an argumentative (philosophical) 
activity dealing with another (either ordinary or scientific) argumentative activity.

If I now declare that I favour what's usually called the firstorder construal of metaphilosophy for which "the application of philosophy to philosophy itself, is simply one more instance of philosophy" (Joll 2017; cf. Wittgenstein PI-§121; cf. Williamson 2007, p. ix), it is clear that the reader of this paper is dealing with no less than three argumentative layers: the metaphilosophical one (my own discourse), the philosophical one (discourses about the justification of abduction), and the philosophical object one (either common or scientific uses of abduction). These should be, on the one hand, clearly distinguishable and, on the other, understood and dealt with using the same practical and conceptual tools. ${ }^{1}$

Keeping all this in mind, section 2 will just try to clarify, for the purposes of the present discussion, my own argumentative account of abduction as developed in previous papers (Olmos 2019a; 2019b; 2020a). Section 3 will show different argumentative ways philosophers have assayed the global justification of abduction, some of which $(3.1,3.2,3.3,3.4)$ simply demand normative restrictions that are rather compatible with the usual critical assessment of particular abductive arguments (represented by the critical questions assigned to its argumentative scheme), while others (3.5) try to reach a deeper level of discussion in which the very grounds of "what constitutes a reason for what" are directly confronted. Finally, some conclusions about the nature of these discussions are offered in section 4 .

\section{Argumentative approaches to abduction ${ }^{2}$}

Since D. Walton's (2004) extensive monographic work, Abductive Reasoning, there have been some distinct argumentative approaches to abduction - probably not as many as could have been

\footnotetext{
${ }^{1}$ This is not necessarily so, as long as philosophers could claim to use argumentatively distinct strategies and grounds. However, although this cannot be dealt with here, my contention is that there is nothing fundamentally distinctive in philosophical argument. I'll make some comments about this in the Conclusion section.

2 This whole section is based on previous work (Olmos 2019a, 2019b, 2020a). Concrete quotations will not be indicated in the body of text.
} 
expected, but certainly covering different trends within argumentation theory. Walton's work is based on the methodology of dialogue types, offering both a dialogical model of explanation and a dialogical model of the justification of the best explanation (which is, for him, equivalent to abduction). Wagemans's approach (2016) is pragma-dialectical, and $\mathrm{Yu}$ and Zenker (2018) employ a methodology of argumentation schemes (with a traditional premisesconclusion model) plus critical questions.

Although not explicitly framed within the field and methodologies of argumentation theory, Josephson's approach (cf. Josephson and Tanner 1996; Josephson 2000, 2001) is rather akin to some of their concerns. Josephson makes and uses a distinction between abductive argument and abductive reasoning (2000, p. 35; 2001, pp. 1624-1632) that I have also emphasized elsewhere (Olmos $2019 \mathrm{~b}$ ) and carefully examines how abductive arguments get dialogically evaluated by a series of considerations that question the strength of their justification.

Strangely though, Josephson calls his approach to abduction as a reasoning, mental process "the dynamic perspective" (2001, p. 1632), whereas I would say that his argumentative and dialogical approach is much more interactive and attentive to the continuity and interativity of justificatory exchanges, and so dynamic in a more interesting way. In this sense, I especially like the treatment offered by Josephson (2001, pp. 1629-1631) where the author contemplates not only the undercutting function of his five evaluative considerations regarding an abductive proposal, but also the possible defences or supporting moves that might confront them in a continued exchange.

My own proposal, as presented in other papers, is based on a conceptual emphasis on three distinctions:

a) the (already mentioned) discrimination between mental processes of reasoning and communicative exchanges of giving reasons;

b) a careful distinction between the communicative acts of explaining (i.e., giving explanatory reasons) and communicative acts of arguing (i.e., giving justificatory reasons); and 
c) an analysis of simple abduction as a distinctive argumentation scheme based on a characteristic kind of reasonfor-a-conclusion - and, thus, a characteristic kind of warrant in S. Toulmin's (1958) sense-as opposed to IBEtype exchanges: complex and varied (typically dialogical and intrinsically dialectical) communicative processes of selecting, assessing, and weighing alternative explanatory hypotheses, purporting the use of varied argumentative, counterargumentative, and metaargumentative schemes and structures.

As point c) makes clear (and contrary to Walton or $\mathrm{Yu}$ and Zenker), I propose a model of abduction based on a distinctly Toulminian argumentation scheme (in which the distinct identifying and clarifying role of the warrant is duly emphasized $)^{3}$ supplemented with analytic tools accounting for inter, counter, and meta-argumentative structures. ${ }^{4}$ In agreement with this theoretical framework, I offer the following characterization of the act of presenting an abductive argument:

[Ab-Arg] presenting, within a communicative interchange, an abductive argument is to publicly support a claim that is, in principle, theoretical or factual - typically mentioning either unobservable or merely unobserved entities, properties, and processes - on the basis of shared data, either observable, well-known, taken for granted, or assumed, precisely since that claim could provide some conceivable explanation of them.

The basic definitional elements of an "abductive argument" understood according to the model of a Toulminian argumentative scheme are:

\footnotetext{
3 “" $[\mathrm{t}]$ he warrant is, in a sense, incidental and explanatory, its task being simply to register explicitly the legitimacy of the step involved and to refer it back to the larger class of steps whose legitimacy is being presupposed." (Toulmin 2003 [1958], p. 92).

4 These tools are best described in a series of papers by H. Marraud: cf. https://uam.academia.edu/hubertmarraud.
} 
1. Conclusion/Claim: an "explanatory hypothesis" $\mathrm{H}$, usually presented as a factual statement, although, depending on the requirements of the context, it may be easily reinterpreted as a practical or even an evaluative conclusion of the kind: "we should explore hypothesis H"; "Hypothesis $\mathrm{H}$ is worth exploring."

2. Reasons/Data: usually empirical and observable ${ }^{5}$ but in any case presented as shared or agreed upon data, and nevertheless surprising data, that is, data requiring explanation (which makes them a potential explanandum). However, this preparatory condition might be contested in an ensuing discussion. ${ }^{6}$

\footnotetext{
${ }^{5}$ I consider the observable character of the phenomena presented as agreed data in an abductive argument a relative condition that is, of course, subject to possible discussions and alternative interpretations on the part of the interlocutors and that is particularly mediated by the kind of admissible evidential means and techniques in different practices, settings and contexts. The context and theory-dependent character of what's observable is a current assumption of epistemology and philosophy of science. However, somewhat opposing the dissolving character of the radical thesis of observation's theory-ladenness advocated by many philosophers of science in the 60-70s, Hacking (1983, ch. 10) has claimed that we may acknowledge the meaningfulness of the theory/observation divide as related to particular discussions and settings in which entities and processes are presented and evaluated as either observed or theorized depending on the roles they are going to play in the discussion.

${ }^{6}$ Contesting the fulfillment of this condition in a concrete case might be the result of different considerations. The other party might adduce that the data are not in need of an explanation because they are what was expected and are thus currently understood and fully explained (cf. Toulmin's [1961] ideals of natural order). But the opponent might also consider that the set of data, as presented, are nothing but noise and do not really constitute any well-defined phenomenon from which to set forth in search of an explanation. Josephson (2001, p. 1628) calls that kind of rejoinder a defense of the "NOISE hypothesis" that would "explain away" instead of "explain" the data and places this possibility alongside the alternative hypotheses to be considered in a thorough evaluation of an "inference to the best explanation," which is, for him, equivalent to abduction. I prefer, though, not to characterize this kind of suggestion as an alternative hypothesis but as a counter-argument attacking the very presentation, assertion, and characterization of the data as a prospective explanandum. Such counterargument might already appear at the moment of evaluating a simple abductive argument when there is still no weighing of alternative hypotheses.
} 
3. Warrant: what makes the data a justificatory reason for the conclusion (the hypothesis) is that such hypothesis could explain them.

These elements may be represented and diagramed thus:

Warrant: Hypothesis could explain data

Data: Shared (usually empirical) data

So

\section{Claim: Hypothesis}

It could be pointed that the kind of warrant I am proposing for abductive arguments is not exactly "of a more general scope" than the data and the claim of the argument, referring exactly to the same items as its basic constituents. ${ }^{7}$ Nevertheless, this is just apparently so because such a warrant introduces between these items a substantive kind of relation, namely explanation, that may respond as well to a variety of principles or explanatory warrants on which it may be based. The concretion of the kind of explanans that the hypothesis is vis-à-vis the observable data (taken as explanandum) provides the degree of principled generality that an argument requires to be so recognized and understood (and eventually assessed) by an interlocutor. ${ }^{8}$

7 This condition, if confirmed, would be against my own understanding of Toulminian warrants (Olmos 2020b, p. 70), although not necessarily against the understanding of other scholars (cf. Bermejo-Luque 2006).

${ }^{8}$ I seem to be assuming here a generalist stance (as defined by Dancy 2004, p. 7) regarding explanations as based on warrants that could be opposed to the particularist idea that, in many cases, explanations can be grounded on the individual case's concrete conditions without "invoking" any general principle. Challenging Hempel's nomological model of explanation (Hempel 1965), Scriven claimed, for example, that "Producing laws is one way, not necessarily more conclusive, and usually less easy than other ways of supporting a causal statement. In history and psychology there are very well established ways of directly supporting such statements which do not involve stating laws such as those in physics" (Scriven, 1962, p. 195). More recently, scholars discussing narrative explanations have also opposed such nomological models on particularist grounds (Roth 1989; Richards 1992; Crasnow 2017; cf. Olmos 2020c). I am more than sympathetic to these anti-Hempelian contentions and even to the possibility of construing particularist accounts of argument and explanation emphasizing the basic role of analogy in lieu of warranting principles in evalu- 
According to this idea, and taking into account the structural homogeneity between argument and explanation as the products of pragmatically different acts of giving reasons (Álvarez 2016), it is possible (and, more importantly, useful) to construe an "expanded diagram" of the abductive argument, including the details of the related explanation - an explanation that is not exactly given in the abductive argumentative act but just mentioned or alluded to as what makes the empirical data a justificatory reason for the (theoretical) hypothesis - as follows:

\begin{tabular}{l|c|c|} 
& \multicolumn{1}{c|}{} & Empirical data \\
\cline { 2 - 3 } & Hypothesis & \\
\multirow{2}{*}{$\begin{array}{l}\text { Explanatory warrant: } \\
\text { principle/ideal X: }\end{array}$} & That's why & So \\
\cline { 2 - 3 } & Data & $\begin{array}{c}\text { Explanatory hy- } \\
\text { pothesis }\end{array}$ \\
\hline
\end{tabular}

The way this kind of argument comes to be assessed in argumentative exchanges is made explicit in its particular list of critical

ating reason-giving acts. However, even if I cannot discuss here all the aspects of this issue, I should say that (be they explanatory or justificatory) Toulminian warrants cannot be equated, neither conceptually nor functionally, to Hempelian laws seeking deductivist validity and theoretical commitment. Those "well established ways" mentioned by Scriven as operative in history and psychology could well be the basis of explanations that are recognized as such thanks to practical or methodological warrants that do not work as theoretical statements about the world. Moreover, the explanatory warrants I mention here are not a necessary element of the explanans's justificatory strength and derivative force, the element that precisely achieves the result that the explanandum may follow from it. They are, instead, a way to "verbalize," when and if need be, the kind of explanatory relation that mediates between them and that could be unique, fully innovative, and operate at various levels. Finally, admitting the possibility (and even the cognitive and genealogical priority) of arguing and explaining without resorting to established patterns (i.e., to argumentative and explanatory schemes represented by expressible warrants) does not imply the uselessness of describing the usual and conventional patterns that the members of a certain society invoke and learn to recognize in their established practices. 
questions or ways of questioning it that also functions as a systematic map of the possible counterarguments it may face.

In the case of abduction, the critical questions could be the following: ${ }^{9}$

\section{a) Procedural or dialectical questions, source of possible dismissals:}

CQ1. Is abduction an admissible type of argument (or even an explicitly admitted one) in the current context or concrete argumentative activity involved?

CQ2. Should the arguer rather continue advancing evidence and reasons, considering the conclusion not yet sufficiently justified? Is the context such that it demands more reasons, apart from explanatory power, to consider the conclusion to be justified? ${ }^{10}$

\section{b) Questions about the data, source of possible counterar- guments by objection:}

CQ3. Are the adduced data reliable? ${ }^{11}$

CQ4. Are the adduced data all the available data?

CQ5. Has data research and gathering been as complete and exhaustive as the context or particular argumentative activity involved requires? ${ }^{12}$

\footnotetext{
9 This is an improved list from the one offered in previous works and it is ordered according to the classification of modes of counter-argument proposed by Marraud (2020). Many of the concerns raised by these critical questions appear (in a very similar way) in Josephson and Tanner's (1996, p. 11) six and in Josephson's (2001, p. 1626) five considerations on which the strength of the abductive or IBE conclusion depends (I will mention the equivalences). However, I consider that the ordering of the critical questions according to a systematic categorization of counter-argument types gives better coherence to the set while maintaining an open character with no claim to exhaustiveness.

${ }^{10}$ CQ2 raises similar concerns to Josephson's "pragmatic considerations" (\# 5-6 in Josephson and Tanner 1996; \# 4-5 in Josephson 2001): "4) how strong the need is to come to a conclusion at all, especially considering the possibility of gathering further evidence before deciding; and 5) the costs of being wrong and rewards of being right."

${ }^{11}$ Cf. Josephson and Tanner's (1996) consideration \#3.

${ }^{12}$ Cf. Josephson and Tanner's (1996) consideration \#4 and Josephson's (2001) consideration \#3.
} 
c) Questions about the warrant, source of possible rebuttal counterarguments:

CQ6. Is the concluded hypothesis explanatory according to a recognizable and accepted explanatory pattern, or could an acceptable pattern issue from its proposal?

CQ7. Is the concluded hypothesis a good explanation according to the conditions ${ }^{13}$ of that particular explanatory pattern?

d) Questions about the conclusion, source of possible simple refutation counterarguments (i.e., reasons for noH):

CQ8. Is there any known reason to consider the conclusion false? ${ }^{14}$

e) Questions about the conclusion, source of possible comparative refutation counterarguments (i.e., reasons for alternative $\left.\mathbf{H}^{\prime}\right)$ :

CQ9. Have other alternative explanations been explicitly advanced regarding the same data?

CQ10. Could other alternative explanations be reasonably conceived according to the usual procedures of the context or practice involved?

f) Questions about the comparison between alternative conclusions, source of weighing metaarguments:

CQ11. Is there any reason to believe that the conclusion $(\mathrm{H})$ offers a better explanation of the data than the alternative ones $\left(\mathrm{H}^{\prime}\right.$, $\left.\mathrm{H}^{\prime \prime}\right)$ ? $^{15}$

\footnotetext{
${ }^{13}$ Here we would need to refer to a new list: the list of critical questions attached to the particular explanatory scheme used in the case. This kind of work is still to be approached within the proposed framework.

${ }^{14}$ Cf. Josephson and Tanner's (1996) and Josephson's (2001) consideration \#2.

${ }^{15}$ Cf. Josephson and Tanner's (1996) and Josephson's (2001) consideration \#1. Note that the order in which my critical questions approach the evaluation of an abductive argument is exactly the opposite of Josephson's considerations. This is consistent with my recognition of a distinctly abductive argument scheme that may not necessarily involve an IBE-type exchange.
} 
Some of these current and stereotyped ways of questioning an individual abductive argument will come out again in the philosophical discussions about the justification of abduction itself. However, argumentative models of abduction are not really my topic in this paper. All these models, in fact, assume both the widespread presence of abductive arguments in a variety of argumentative practices and their evaluable character, proceeding then to determine ways in which abductive arguments are in fact or should be assessed. But these conditions are precisely the nub of what is at stake in philosophical discussions about the justification of abduction. At least in principle, although, depending on the particular solution provided by an individual philosopher, they might be questioned to a greater or lesser degree.

\section{Philosophical discussions of the justification of abduction}

The idea of a philosophical discussion of the justification of abduction is to discuss the grounds themselves that allow for the understanding, conception, and presentation of abductive arguments. Using Toulminian terminology, these would discuss up to what point the kind of (substantive) link between the data and claim invoked in an abductive argument (and expressed in its warrant) makes the data a justifying reason for that claim. Thus, such philosophical debates might be considered warrantdiscussing argumentative activities aimed at establishing warrants (or warrant-types; cf. Toulmin 2003 [1958], pp. 111-113, 125126).

According to these ideas, philosophical discussions of the justification of abduction might be modelled as constituting either a restricted or a more radical, but, in any case, a reasoned (and argumentative) critical assessment of the following scheme in which "H explains D" (or " $\mathrm{H}$, that's why D") is taken as a reason to support that "D justify H" (or "D, so H"): 
Warrant: That a hypothesis explains some data is a reason to consider those data to be a justifying reason for that hypothesis:

Reason: Hypothesis explains data

\section{So}

Claim: Data justify hypothesis [hypothesis can be inferred from data]

For the purposes of my discussion, I will, in fact, be using more expanded versions of this same scheme as follows:

\begin{tabular}{|c|}
\hline Hypothesis \\
\hline That's why \\
\hline Data \\
\hline
\end{tabular}

That a hypothesis explains some data is a reason to consider those data to be a justifying reason for that hypothesis:

So

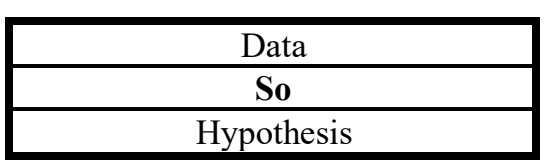

That a hypothesis explains some data is a reason to consider those data to be a justifying reason for that hypothesis:
Hypothesis

In virtue of "explanatory principle X":

That's why

Data

So

Hypothesis can be inferred from data

Now, if you ask what kind of reason could that one be for such a claim? the answer should be expressed by the warrant I have provided, which is, I must agree, frustratingly redundant and so kind of useless. It might be considered (taking into account how it is articulated) a "more general" statement than the argument it 
covers, but it surely does not add any new substance to it beyond formal or informal subsumption (depending on quantification).

This is a problem according to my own reading of Toulmin's warrants (Olmos 2020b, p.70) as having (if verbalized at all) the following properties:

i) They have a general but typically not universal character (i.e., they are typically not universally quantified) and

ii) They express a substantive as opposed to a formal relation between reason and claim (i.e., they always mention a respect, a concept, containing the alleged kind of link between reason and claim that goes beyond formal derivation).

However, I will advance two excuses for this: a deep philosophical one and a more pragmatical one. The first is that we might be reaching a really deep (cognitive, logical) level of what counts as a reason, not really based on more reasons-for-reason-being than sheer intuition. ${ }^{16}$ But, this is really what is at stake and what some philosophers (such as those mentioned in 3.5) really try to handle by suggesting and discussing possible Toulminian backings for such a rule.

The other excuse is simply practical. Such a scheme (as will be shown in what follows) makes room for both the philosophically deeper challenges and the more accommodating (and qualified) restrictions on the use and acceptability of abductive arguments that different authors have advanced and is, therefore, a useful and expedient instrument to compare and classify them, which is my main aim in this paper.

Now, philosophers such as J. Woods, I. Hacking, J. R. Josephson, P. Lipton, B. van Fraassen or I. Douven (some of them precisely interested in attacking or defending "scientific realism") have discussed abduction starting with the idea that it is not a

\footnotetext{
${ }^{16}$ Naturalistic hypotheses for the genealogical and functional effectiveness of such intuitions have been advanced by Woods (2017) and by Mercier and Sperber's recent "argumentative theory of reasoning" (Mercier and Sperber 2011, 2017).
} 
mode of reasoning and arguing that could be unqualifiedly or unrestrictedly admissible. So their strategy is to demand additional restrictions or well-defined conditions under which such a generic scheme (and therefore, the particular abductive arguments generated by it) could be accepted. Five such modes or levels of restriction might be identified in philosophical literature and will be described in the following subsections.

\subsection{Global dialectical/procedural restriction (or field limitation)}

[GR] The generic scheme, and so the use of abductive arguments, might be admissible in some argumentative fields while not in others; for example, it is all right to use abductive arguments in everyday life but not in scientific inquiry.

Such global restrictions governing possible dismissals (as suggested by CQ1 and CQ2) are usually made dependent on considerations regarding:

i) The higher or lower degree of certainty demanded for claims in the particular field involved.

ii) The greater or lesser need (or institutional obligation) to reach a conclusion.

These two kinds of consideration obviously pull in different directions when it comes to deciding whether to admit abductive arguments within a particular argumentative practice, taking into account the need to yield a balanced decision. They could be thought of as also being regulated, at a deeper and less institutional level, by Josephson's pragmatic (and recognizably pragmatist) consideration of "the costs of being wrong and rewards of being right" (Josephson 2001, p. 1626).

B. van Fraassen's contention about the non-scientific character (because of going beyond a healthy and mandatory empiricism) of conclusions based on abduction is a good example of this kind of proposed restriction based on the specific principles of a recognized argumentative activity, namely science:

A person may believe that a certain theory is true and explain that

he does so, for instance, because it is the best explanation he has 
of the facts or because it gives him the most satisfying world picture. This does not make him irrational, but I take it to be part of empiricism to disdain such reasons (van Fraassen 1985, p. 252).

\subsection{Claim restriction (related to the argument's sufficiency)}

[CR] The generic scheme, and so the use of abductive arguments, might be admissible by adjusting the mode of validity aimed at by its claim (or the kind of claim presented by its conclusion).

In his paper on the logic of abduction, Woods emphasizes what he sees as one of Peirce's insights: "Rather than believing them, the proper thing to do with abduced hypotheses is to send them off to experimental trial. (CP, 5. 599, 6. 469-6. 473, 7. 202-219)" (Woods 2017, p. 138). According to this idea, abduction may not really provide reasons (enough? any?) to assert the hypothesis as a factual claim but may function as a "practical argument" supporting a directive act in the following way:

That a hypothesis explains some data is a reason to consider those data a justifying reason to experimentally test

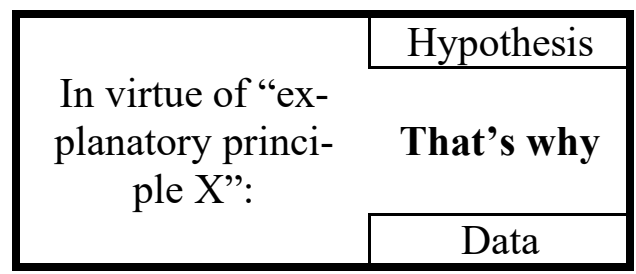
such hypothesis:

\begin{tabular}{|c|}
\hline Data \\
\hline So \\
\hline $\begin{array}{c}\text { Hypothesis should be empirical- } \\
\text { ly tested }\end{array}$ \\
\hline
\end{tabular}

Now, using somewhat similar intuitions, Hacking, in Representing and Intervening (1983, pp. 271-272, cf. also Hacking 1984, p. 
167) mentions the insufficiency of abduction, that is, of the mere explanatory power or success of a hypothesis, to support a "realist claim" regarding a theoretical entity (e.g., the electron) that is among the posits of that particular hypothesis.

Hacking's point is that we are finally justified in supporting such a "realist claim" as a theoretical statement about the entity's "existence" only when our experimental practices have allowed us:

a) to (directly/indirectly) detect the entity, and

b) to effectively manipulate it in further experiments unrelated to its establishment (cf. Douven 2002, pp. 360-362).

Hacking's suggestion might be argumentatively modelled as requiring for the sought for conclusion (the assertion of the hypothesis) a conjunction of arguments (Marraud 2013, pp. 59-62) which functions as coordinative argumentation (Snoeck-Henkemans 2003).

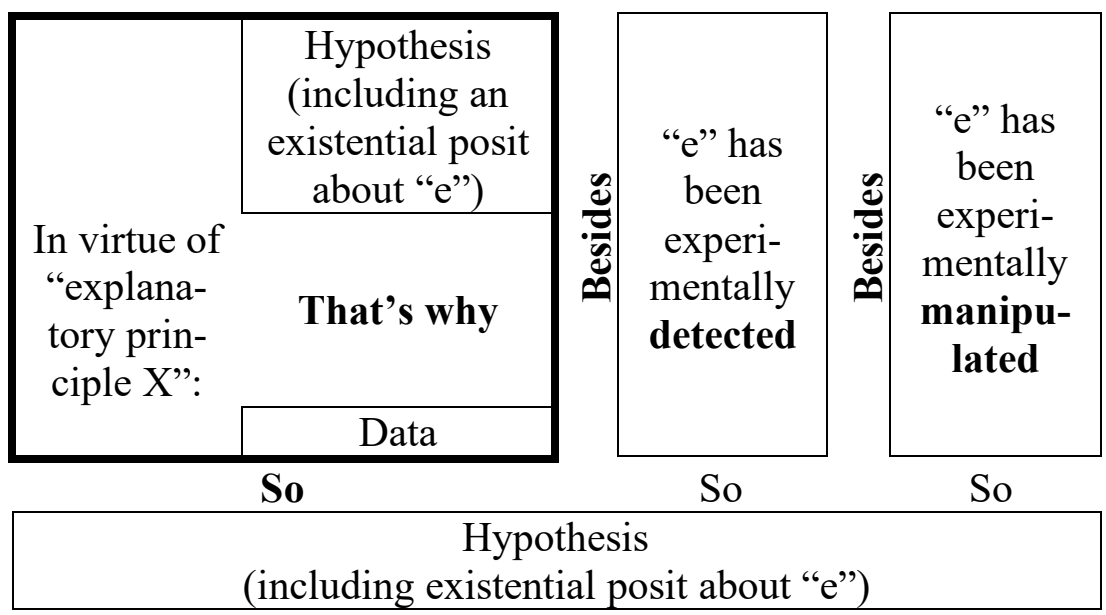

So, even if Hacking's position has been rendered a critical one regarding the place of abduction in scientific justification, I think his stance is better understood as just mitigating its power to establish a theoretical conclusion. 


\subsection{Restriction over acceptable explanatory principles}

A different kind of discussion arises when one concentrates on the idea that explanations, as it happens with arguments, may also be classified according to the diverse kinds of "explanatory warrants" they are based on. A possible answer to the admissibility of abduction makes it dependent on the kind of associated explanation that serves as its warrant. In this case:

[EPR] the generic abductive scheme and so the use of abductive arguments might be admissible just in case some normative requirements are placed on it regarding three different aspects:

[EPR1] A restriction over the kinds of explanation (or explanatory principles) acceptable in a given field. This restriction might be added to the diagram of an acceptable abduction as follows:

That a hypothesis explains in such a way some data is a reason to consider those data a justifying reason for that hypothesis:

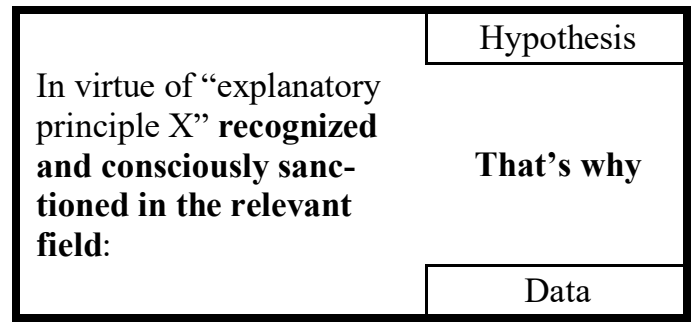
tioned in the relevant field:

Data

\section{So}

Hypothesis can be inferred from data

This is precisely what is at stake in contemporary philosophical discussions about the notion of "mechanism" as the basis of scientific explanations (Machamer, Darden, and Craver 2000; Psillos 2011; Glennan and Illari 2016). Such discussions revive, in some way, after the positivists' conscious avoidance of metaphysical inquiries about causation and causalist vocabulary, the $19^{\text {th }}$ century 
methodological reflections on the (Newtonian) concept of true cause or vera causa (cf. Scholl 2020).

[EPR 2] A restriction of the quality of such an explanation, based on standardized criteria associated with the "explanatory principle" in case.

In the following diagram, what would really be the conclusion of a process of critical assessment of the explanation is represented as an additional premise.

That a hypothesis

\begin{tabular}{|c|c|c|}
\hline & Hypothesis & \\
\hline $\begin{array}{l}\text { In virtue of "explana- } \\
\text { tory principle X" } \\
\text { recognized and } \\
\text { consciously sanc- } \\
\text { tioned in the rele- } \\
\text { vant field: }\end{array}$ & That's why & $\begin{array}{l}\text { It is a good } \\
\text { (enough) } \\
\text { explanation } \\
\text { according to } \\
\text { X's condi- } \\
\text { tions }\end{array}$ \\
\hline & Data & \\
\hline
\end{tabular}

explains in such a way some data is a reason to consider those data a justifying reason for that hypothesis:

I have already mentioned (see footnote 13) the ramification implied by the necessity to take into account the "critical questions" associated with the invoked explanatory scheme when assessing an abductive argument. This is a result of the embedded (or structural) character of abduction as a meta-explanatory argument (Olmos 2019b) and a token of the open-ended and critical nature of argumentative conclusions.

That hypotheses must fulfill certain conditions of their own regarding their "explanatory power" is a consideration that may operate both at the level of assessing a simple abduction (a source of discarding rebuttals for it) or as a checking proviso once the proposed hypothesis has survived a comparative process as the 
best explanation of a certain lot. There is, in this sense, a widespread concern among philosophers that being the best might not be enough. ${ }^{17}$ This has led some defenders of IBE, such as P. Lipton, to conceive of it as a two-stage process (Lipton 2004, Ch. 9) in which the individual assessment of each candidate, as Fisher puts it, "insures that IBE does not permit a person to believe any hypothesis -however bizarre- as long as it's the best of her options" (2014, p. 1060).

[EPR3] Finally, a further restriction could be called for regarding the comparative quality of the explanation vis-à-vis alternative explanations.

Here, again, what would, in most cases, really be the conclusion of a complex argumentative process is represented as just an additional premise.

That a hypothesis

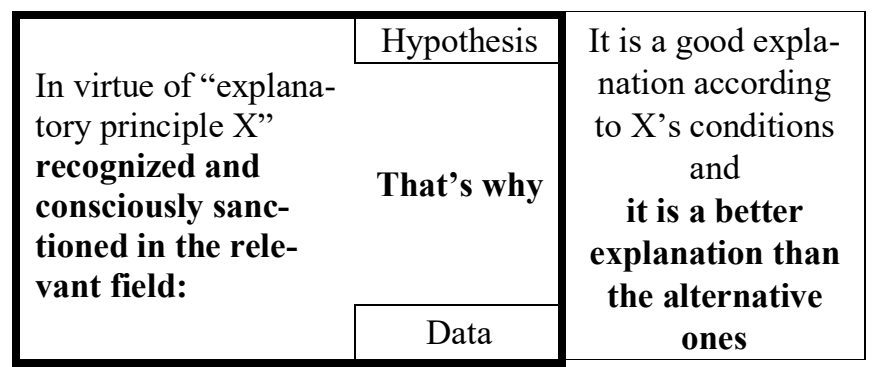

explains in such

a way some data

is a reason to

consider those

So

data a justifying

reason for that

hypothesis:

Hypothesis can be inferred from data

The interest of such a justification process in itself has led many philosophers to concentrate on it, claiming that it is the true key to

\footnotetext{
${ }^{17}$ Fisher calls this concern "Bas van Fraassen's 'best of a bad lot objection"" (2014, p. 1060).
} 
the assessment of abduction, which could only be acceptable and even assessable under the model of an "inference to the best explanation" or IBE. ${ }^{18}$ The next kind of restriction in our classification accounts for this idea.

\subsection{Balancing restriction (stipulation of comparative weighing)}

Philosophers such as Douven (2017) defend a position that could be understood under the following lemma:

[BR] Abduction is only justifiable under an IBE model.

That means that emphasis is placed on the justification process of the comparative premise: "It is a better explanation than the alternative ones."

Now, according to my own analysis (Olmos 2019b), this implies the systematic weighing of the arguments supporting each alternative explanatory hypothesis, and that can be very different and based on different warrants. Thus, my claim is that there cannot be a rigid universal model of IBE-type argumentation. ${ }^{19}$ In

${ }^{18}$ The admission among the critical questions associated with simple abduction of those who mention and take care of alternative hypotheses seems to lead to the conclusion that any abductive proposal would end up being evaluated under an IBE model. However, as I have claimed in previous papers, I want to defend the usefulness of keeping the distinction between simple abduction and IBEtype discussions in terms of the argumentative tools demanded for their description and analysis. While abduction can be represented by a distinctive argumentative scheme and a distinctive warrant, an evaluative process leading to the selection of the best (available) explanation is going to demand the employment of complex dialectical (interactive) and logical (structural) inter-, counter- and meta-argumentative categories and, in most cases, the allegation of other kinds of reasons purporting to further non-abductive argumentative schemes.

${ }^{19}$ I claim that there cannot be a rigid universal model of IBE and that, consequently, IBE can be considered neither a characteristic type of inference, nor a stereotyped argumentative sequence, and so the very label IBE should be rejected. These are precisely the radical conclusions that Fisher wants to avoid at all costs and that lead him to reject the possibility of contextualizing to a greater extent than he already does the compliance of the theoretical virtues in the case of the alternative hypotheses: "We have good reason not to go the latter route. For suppose we were to do so. Then, we would not be thinking of IBE as a single form of inference, but rather as a family of different inference forms [...] there would be no way to mount a general defense of IBE's epistemic credentials: we would have to evaluate each inference form on its own, in its 
any case, among the simplest (and probably most interesting) possibilities, we may mention the comparison between two abductive arguments (each supporting an alternative explanatory hypothesis) based on the superiority of one of the involved explanatory principles over the other. This could, in turn, be a generally recognized superiority at least in the relevant field (as represented in the following diagram), or a more nuanced superiority related to conditions of the particular case. ${ }^{20}$

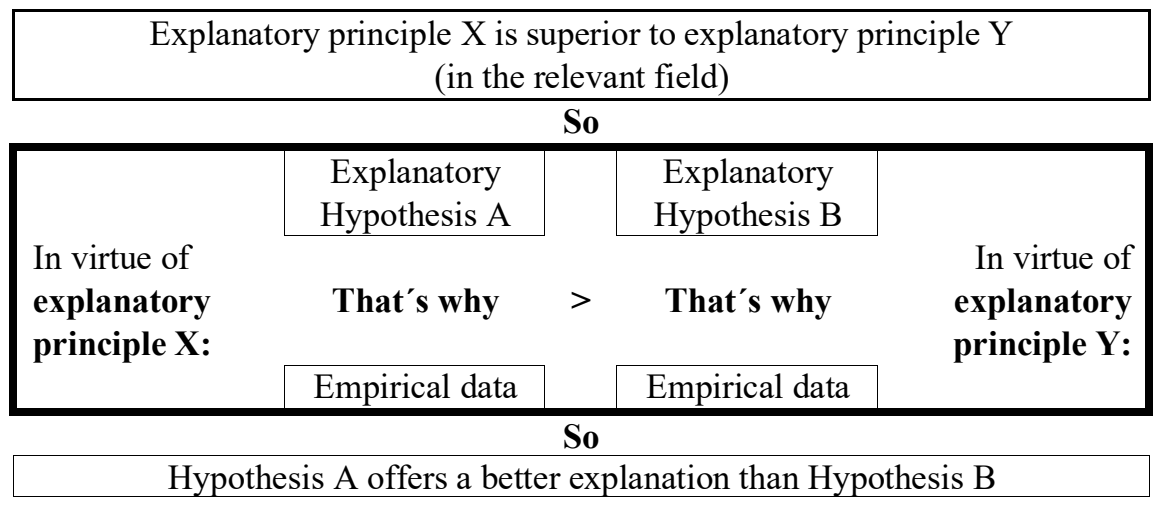

\subsection{Epistemic restriction (or backing-request)}

So far, the ideas advanced by different authors for a qualified acceptance of abduction as a prima facie plausible and assessable mode of arguing, even if conducted in a universal and allegedly

appropriate context. Moreover, such a view flies in the face of the hope $[\ldots]$ that IBE can be understood as a basic form of inference [...] then this project is hopeless" (Fisher, 2014, p. 1064). My argumentative approach certainly opposes certain conceptual routes and particularly avoids an inference-account of IBE (and even of abduction). The idea is that it is in public argumentative practice that we dialectically assess our modes of reasoning and arguing, according sometimes to learned stereotyped patterns but in ways that are always open to further rational demands that allegedly conclusive inferential models try precisely to circumvent. As I have argued elsewhere, this might be bad news for certain philosophical projects, but there is a reward (or consolation) in our being able to describe with greater detail and sensitivity our argumentative and justifying practices.

${ }^{20}$ Alexy's weight formula or law of balancing (2003) would be of the second kind as it takes into account the particular way in which the contending principles are complied with in the case. 
conceptual way, do not really go much beyond the usual criteria we are accustomed to in assessing particular abductions as establishing stronger or weaker arguments.

Thus, the critical questions usually associated with abduction as an argumentative scheme may easily take care of requirements such as those expressed in 3.1 (usability of the scheme in a certain context, CQ1-CQ2), 3.3 (grounds and quality of the associated explanation, CQ6-CQ7), and 3.4 (comparison of claimed hypothesis with alternative hypotheses, CQ9-CQ11). So, finally, what these kinds of (philosophical) restrictions really amount to is the acceptability of good-enough abductions.

Concerns expressed in 3.2 are probably harder to accommodate in such a methodology, as they address the very definition and comprehension of abduction itself as a theoretically or pragmatically bounded (and accordingly evaluated) way of reasoning and arguing. But still, the abductive principle is taken for granted. If we address these concerns framed in terms of sufficiency, critical questions like CQ2 and CQ8 might take care of them.

However, even if this is so, important conceptual and theoretical differences must be acknowledged between treating such considerations and ways of questioning abductive arguments as truly "critical questions," that is, as questions and concerns that may arise whenever an abduction is presented to others to be dialectically and dialogically assessed or as conditions an abduction needs to fulfil in order to be considered admissible or even well-formed in a certain context. Although the same possible "weak points" or vulnerabilities of abductive reasoning might be identified in these contrasting approaches, what differs in them is the very conception of argument assessment, either as an open argumentative practice of the interlocutors or as a task to be completed and established (for good?) by the philosophical experts.

In any case, this coincidence with concerns raised by the critical questions does not appear anymore in discussions of precisely the tenability of the principle or warrant itself (i.e., that a hypothesis explains some data is a reason to consider those data a justify- 
ing reason for that hypothesis) as an epistemic rule. ${ }^{21}$ If we question a principle acting as a warrant - that is, not its limits or the scope of its applicability, but the tenability of the principle itselfthe defensive move would constitute an attempt to "back" it, that is, to find reasons in its favor, to use Toulmin's terms (Toulmin 2003 [1958], pp. 95-100).

That is what I consider P. Lipton $(1993,2004)$ or B. van Fraassen (1989) to be trying to do, albeit adducing completely opposite intuitions (cf. Douven 2002, pp. 356-360) and philosophical agendas. Thus, Lipton, who wants to defend the justified character of abduction (and, with it, the feasibility of scientific realism) enunciates an optimistic "epistemic principle" as the appropriate backing for our warrant: "the loveliest explanation is probably the likeliest explanation" - that is, the kind of virtues we value in explanations are the kinds of virtues that assess their likelihood or, in other terms, theoretical virtues are truth-conducive (cf. Fisher, 2014). My impression is that this kind of backing is somewhat redundant (again) but makes explicit the kind of hopeful belief behind our abductive behavior. The move of adducing it as a backing for the discussed warrant or principle can be diagramed thus:

\begin{tabular}{|c|c|}
\hline $\begin{array}{c}\text { The loveliest explanation is } \\
\text { probably the likeliest expla- } \\
\text { nation }\end{array}$ & \\
\hline So & $\begin{array}{l}\text { Hypothesis explains data in virtue of explana- } \\
\text { tory principle X" recognized and consciously } \\
\text { sanctioned in the relevant field, it offers a } \\
\text { good explanation according to X's conditions, } \\
\text { and it is a better explanation than the alterna- } \\
\text { tive ones }\end{array}$ \\
\hline \multirow[t]{2}{*}{$\begin{array}{l}\text { That a hypothesis explains in } \\
\text { such a way some data is a } \\
\text { reason to consider those data a } \\
\text { justifying reason for that } \\
\text { hypothesis }\end{array}$} & So \\
\hline & Hypothesis can be inferred from data \\
\hline
\end{tabular}

21 The terms and context of such a discussion need not be focused on purely "epistemic" concerns, but in fact this is what we mainly find in philosophical literature. 
Lipton's line of defense is akin to the idea that somehow we have identified and are able to invoke the kind of characteristics that make an explanation both theoretically lovely and epistemically likely. Such a hope could be, in its turn, further justified by naturalistic evolutionary assumptions like those expressed by $\mathrm{J}$. Woods's naturalized logic: "Take it as a given in the absence of particular reasons to the contrary that humans reason well when they reason in ways that humans normally reason in the conditions of real life" (Woods, preprint a, p. 17). Woods has applied his naturalistic and evolutionary causal-response model particularly to abduction:

The "casual response" model offers an alternative route to the normativity of knowledge -and, indeed, of the whole array of knowledge-seeking practices. It likens being good at knowing (at reasoning, problem-solving, etc.) to being good at breathing. It sites this being-good-at in the idea that just as we are built to be good at breathing, so too are we built to be good at knowing (reasoning, problem-solving) (Woods, preprint b, p. 11). ${ }^{22}$

Evolutionary naturalism could be, thus, a possible route to further back Lipton's hope. But there is a danger here because it could be claimed that this line of argument might lead us to think that we cannot fail in identifying the correct answer to our causal inquiries.

As a philosopher of science precisely arguing on the opposite side from Lipton's, van Fraassen aims at attacking abduction precisely for being the lifeboat for "scientific realism." Van Fraassen considers that the abductive principle could only be established by a rather radical and so polemical epistemic hope: namely, "always or in most cases the correct explanation is among the available alternatives," which, in turn, could only be justified in case "human cognition be almost infallible." (van Fraassen 1989; cf. Douven 2002, 356-360). And this is obviously something quite

\footnotetext{
${ }^{22}$ Woods's paper referred to here as "preprint b" and accessible on his web page corresponds to an actually published paper (Woods 2017) that I also quote below. However, the published version does not contain this (for me) rather clarifying paragraph. It cannot be said, though, that Woods's position in the published text differs substantially from what is claimed in it.
} 
difficult to swallow. Van Fraassen's mode of arguing amounts to the negative assessment (by objection or negation of its premise's acceptability) of the only way he conceives backing the principle warranting the abductive scheme, and that would be diagrammed thus:

\begin{tabular}{|c|c|}
\hline $\begin{array}{c}\text { Human cognition is } \\
\text { almost infallible }\end{array}$ & \\
\hline So & \\
\hline $\begin{array}{c}\text { Always or in most cases } \\
\text { the correct explanation } \\
\text { is among the available } \\
\text { alternatives }\end{array}$ & \\
\hline So & $\begin{array}{l}\text { Hypothesis explains data in virtue of } \\
\text { explanatory principle X" recognized } \\
\text { and consciously sanctioned in the } \\
\text { relevant field, it is a good explanation } \\
\text { according to X's conditions, and it is a } \\
\text { better explanation than the alternative } \\
\text { ones }\end{array}$ \\
\hline \multirow[t]{2}{*}{$\begin{array}{l}\text { That a hypothesis ex- } \\
\text { plains in such a way } \\
\text { some data is a reason to } \\
\text { consider those data a } \\
\text { justifying reason for that } \\
\text { hypothesis: }\end{array}$} & So \\
\hline & Hypothesis can be inferred from data \\
\hline
\end{tabular}

Conscious of such a counter-argument, a moderate naturalist like Woods tries to avoid this possibility by invoking a variety of contexts and activities (including science) in which the acquisition of knowledge through abduction cannot just be supported by invoking a naturally developed ability:

It would be wrong to leave the impression that, on the CR model, knowing things is just a matter of doing what comes naturally. There are ranges of cases in which knowledge is extremely difficult to get, if gettable at all. There are cases in which knowledge is unattainable except for the intelligence, skill, training and expertise of those who seek it. Everyone has an aptitude for knowledge. 
But there are cases galore in which aptitude requires the supplementation of vocation and talent - and training. (Woods 2017, p. 143).

A somewhat different and somehow more promising way to defend the abductive principle could be the idea that the mode of reasoning it expresses actually belongs to (rather consensual) "commonsense logic" and so, even if it might be qualified and contextually assessed, its dismissal can only be sustained by an extravagant or out-of-the-way philosophical position or a case of theoretical neglect or insufficiency. Josephson claims, for example, that:

Abductions are abundant, not only in the reasonings and justifications of ordinary life, but also in specialized areas such as medical diagnosis, judicial argumentation, criminal investigations, and scientific reasoning. The familiarity and ubiquity of this pattern of argumentation shows that speakers and hearers share some common understanding of it, and also share a basic agreement that it has persuasive force. Thus, abduction is a part of "commonsense logic." It is quite common, and the most amazing thing is that it has been almost completely unconscious. Abduction appears to have been largely overlooked and underanalyzed by almost 2,400 years of formal logic and philosophy (Josephson 2001, p. 1623).

Josephson's contention can be proposed as an alternative backing for the abductive principle (and so a way of supporting it) based on an argument from consensus gentium:

\begin{tabular}{|c|}
\hline $\begin{array}{c}\text { Everybody understands and recognizes abductive } \\
\text { arguments in a variety of contexts }\end{array}$ \\
So \\
\hline The abductive principle makes up part of "com- \\
monsense logic" \\
So \\
$\begin{array}{c}\text { That a hypothesis explains (in the appropriate way) } \\
\text { some data is a reason to consider those data a justify- } \\
\text { ing reason for that hypothesis }\end{array}$ \\
\hline
\end{tabular}


However, the acceptance of this line of reasoning (particularly its second step) seems to require some further assumptions that are not fully made explicit in Josephson's text. Fisher (2014, pp. 10691072) starts his own defense of IBE (which we can consider applicable to abduction in the context of this paper) with a somewhat similar point but further elaborates it in interesting ways that lead to a dialectical understanding of his position.

Fisher's first contention is that IBE is "a basic source of justification in our theorizing about the world." And he immediately adds:

[w] hen we regard a source of our beliefs as basic, we begin with the assumption that it provides justification [...] And this is for good reason. If we decide not to trust vision until its deliverances have been verified by smell (or vice versa), we will have to wait a long time. So, when we take on a source as basic, we give it the benefit of the doubt (Fisher 2014, p. 1070).

There are two important aspects here that I would like to emphasize. One is the pragmatist justification of the decision-we trust abduction because that is our best alternative to keep goingwhich has all my sympathies. The other is the provisional (assumedly fallible) character attributed to both the source and its yields: abductive conclusions or abducted hypotheses. What we do involves giving them the benefit of the doubt, and this is a dialectical concept.

Contrary to what could be expected, from a narrowly understood epistemic perspective, it is not a question of bestowing a weaker confidence or a lessened belief in factual content as just provisional, but of the particular privileged status, as a reasonable presumption, that a hypothesis gains because it has been argued for as a possible explanation - and the more so if it has been defended vis-à-vis other alternatives as the best explanation available. And this condition places the burden of proof on those who want to overcome such a presumption.

Even if Fisher does not use this dialectical vocabulary of presumptions and burdens of proof, my interpretation of his proposal is rather compatible with his second suggestion to further defend IBE, inspired this time by Chisholm's (1973) particularism (vs. methodism). A particularist strategy, in this sense, would privi- 
lege - and, so, give the benefit of the doubt to-examples of knowledge of which we are confident (in Josephson's sense) and then examine our methodologies to see whether they really identify conditions that are met by these examples, instead of the other way around (Fisher 2014, pp. 1070-1072).

This way of discussing the credentials of abduction and the tenability of its principle restores, in my view, the argumentative nature of its justificatory process and reminds us that we are not (anymore) looking for a priori, transcendental conditions of infallibility or for something like complete justification, but for good reasons to support what is ultimately going to operate, in our rational exchanges, as a Toulminian warrant. And this means a practical principle for characterizing something as a reason for something else, with a certain (never totally defined) range of applicability, subject to exceptions, with typical weak points (represented by its associated critical questions) whose place is public argument and public scrutiny of arguments.

Abductive warrants, as any other argumentative warrant, are there to lead us, after their due examination and discussion, to conclusions and decisions that are only (and only for the time being) "beyond reasonable doubt." 23

\section{Conclusions}

In this paper, I have tried to analyze and categorize, from an argumentative point of view, diverse philosophical approaches and responses to the perceived problem of the justification of abduction.

Part of my interest in this inquiry is to expose not just the argumentative character of philosophical practice (which is a rather widespread assumption) but more precisely its ordinary argumentative character, at least in structural terms. Philosophical argumentation might be understood and modelled with the same structural tools we use to address any other kind of argumentative practice, and it is not necessarily more sophisticated than everyday domestic argumentation in those terms.

23 Philosopher of science Cordero (1991) has used this legal expression to characterize the justified, but still open to revision, status of scientific results. 
It addresses, though, substantive questions that are not ordinarily addressed or probed, and this implies concentrating on somehow deeper (grounding) levels of argument. That is where Toulmin's distinctions come in to help characterize the particularities of philosophical argument. First, there is the distinction between warrant-using and warrant-establishing arguments, which has proved helpful in modelling and understanding discussions regarding "what can be a reason for what" (Cohen 1986).

Even more significantly, it is Toulmin's whole strategy in dismantling the "undifferentiated premises plus conclusion" modeldistinguishing the different roles that argument's constituents play and the different ways to question them - that has helped us to identify specifically philosophical concerns regarding the grounds and principles of principles themselves. Once the iterative and recursive structure of arguing is understood, philosophers' concentration on backings (for both justificatory and explanatory warrants) is a salient feature of philosophical argumentative practice.

Thus, our metaphilosophical itinerary ends up with the centrality (or at least usefulness) of argumentative analysis for the three levels I mentioned in the Introduction:

i) for metaphilosophical practice itself,

ii) for philosophical practice, and

iii) for the reason-giving practices (ordinary or scientific) that are of interest to philosophers.

Acknowledgments: This work has been made possible by funds provided by the Spanish Ministry of Science, Innovation and Universities through Research Project PGC-2018-095941B-100, "Argumentative Practices and the Pragmatics of Reasons." I would like to thank the two reviewers of the article appointed by Informal Logic who have greatly helped me improve it. I especially want to thank J. R. Josephson, who chose to disclose his identity and whose suggestions were precious for the improved version of my paper. I would also like to thank the Informal Logic editors for appointing such helpful and prestigious reviewers. 


\section{References}

Alexy, R. 2003. On balancing and subsumption. A structural comparison. Ratio Juris 16: 433-449.

Álvarez, M. 2016. Reasons for action: justification, motivation, explanation. In The Stanford encyclopedia of philosophy, ed. E. N. Zalta. (Spring 2016 Edition). URL accessed 30 May 30 2021: https://plato.stanford.edu/archives/spr2016/entries/reasons-just-vsexpl/

Bermejo-Luque L. 2006. Toulmin's model of argument and the question of relativism. In Arguing on the Toulmin model, eds. D. Hitchcock and B. Verheij, 71-85. Dordrecht: Springer.

Chisholm, R. 1973. The problem of the criterion. Milwaukee: Marquette University Press.

Cohen, J. L. 1986. The dialogue of reason: An analysis of analytical philosophy. Oxford: Clarendon Press.

Cordero, A. 1991. Evolutionary ideas and contemporary naturalism. In Philosophy and the origin and evolution of the universe, eds. E. Agazzi and A. Cordero, 399-439. Amsterdam: Kluwer Academic Publishers.

Crasnow, S. 2017. Process tracing in political science. What's the story? Studies in history and philosophy of science 62: 6-13.

Dancy, J. 2004. Ethics without principles. Oxford: Oxford University Press.

Douven, I. 2002. Testing inference to the best explanation. Synthese 130: 355-377.

Douven, I. 2017. Abduction. The Stanford encyclopedia of philosophy (Summer 2017 Edition), ed. E. N. Zalta (Accessed May 30 2021). https://plato.stanford.edu/archives/sum2017/entries/abduction/

Fisher, R. W. 2014. Why it doesn't matter whether the virtues are truthconducive. Synthese 191: 1059-1073.

Fraassen, B. van 1989. Laws and symmetry. Oxford: Clarendon Press.

Fraassen, B. van 1985. Empiricism in the philosophy of science. In Images of science: essays on realism and empiricism, eds. P. Churchland and C. Hooker, 245-308. Chicago: University of Chicago Press.

Glennan, S. and P. Illari, eds. 2016. The Routledge handbook of mechanisms and mechanical philosophy. Oxford: Routledge.

Hacking, I. 1983. Representing and intervening. Cambridge: Cambridge University Press.

Hacking, I. 1984. Experimentation and scientific realism. In Scientific realism, ed. J. Leplin, 154-172. Berkeley: University of California Press. 
Hempel, C. G. 1965. Aspects of scientific explanation and other essays in the philosophy of science. New York: Free Press.

Joll, N. 2017. Metaphilosophy. In Internet encyclopedia of philosophy. (Accessed May 30 2021). https://iep.utm.edu/con-meta/

Josephson, J. R. 2000. Smart inductive generalizations are abductions. In Abduction and induction, eds. P. A. Flach and A. C. Kakas, 31-44. Dordrecht: Springer (Applied Logic Series, vol 18).

Josephson, J. R. 2001. On the proof dynamics of inference to the best explanation. Cardozo Law Review 22: 1621-1643.

Josephson, J. R. and M. C. Tanner. 1996. Conceptual analysis of abduction. In Abductive inference: computation, philosophy, technology, eds. J. R. Josephson and S. G. Josephson, 5-30. Cambridge: Cambrige University Press.

Lipton, P. 1993. Is the best good enough? Proceedings of the Aristotelian Society 93: 89-104.Lipton, P. 2004. Inference to the best explanation ( $2^{\text {nd }}$ ed.). London: Routledge.

Machamer, P. K., L. Darden and C. F. Craver. 2000. Thinking about mechanisms. Philosophy of Science 67(1): 1-25

Marraud, H. 2013. ¿Es lógic@? Análisis y evaluación de argumentos. Madrid: Cátedra.

Marraud, H. 2017. Guia de campo de esquemas argumentativos. (Accessed May 30 2021). https:/www.academia.edu/

Marraud, H. 2020. On the logical ways to counter an argument: A typology and some theoretical consequences. In From argument schemes to argumentative relations in the wild, eds. F. H. van Eemeren and B. Garssen, 149-166. Cham: Springer.

Mercier, H. \& D. Sperber 2011. Why do humans reason? Arguments for an argumentative theory. Behavioral and Brain Sciences, 34: 57-111.

Mercier, H. \& D. Sperber 2017. The Enigma of Reason. Cambridge, MA: Harvard University Press.

Olmos P. 2018a. La justificación de la abducción en el contexto del debate sobre el realismo científico: una aproximación argumentative. ArtefaCToS. Revista de estudios de la ciencia y la tecnología 7(2): 35-57.

Olmos, P. 2019a. Un enfoque argumentativo sobre la abducción y sobre la ponderación de hipótesis explicativas. Theoria 34(1): 5-30.

Olmos, P. 2019b. Abduction and comparative weighing of explanatory hypotheses. An argumentative approach. Logic Journal of the IGPL, jzz038 (Accessed May 30 2021) https://doi.org/10.1093/jigpal/jzz038 
Olmos, P. 2020a. Un marco teórico argumentativo para la abducción. In Lógica(S), Argumentación Y Pensamiento Crítico. Didáctica, Problemas y Discusiones, eds. J. Jasso, C. Conforti, E. Jasso, 405-449. Ciudad de México: Editorial Torres y Asociados.

Olmos, P. 2020b. Commentary on T. Blair's "Is there an informal logic approach to argument?". In Proceedings of the 3rd ECA Conference, Groningen 24-27 July 2019, eds. B. Verheij and C. Dutilh Novaes, Vol. I, 67-72. London: College Publications.Olmos, P. 2020c. Revisiting accounts of Narrative Explanation in the Sciences. Some Clarifications from Contemporary Argumentation Theory. Argumentation 34 (4): 449-467.

Psillos, S. 2011. The idea of mechanism. In Causality in the sciences, eds. P. M. Illari, F. Russo and J. Williamson, 771-788. Oxford: Oxford University Press.

Richards, R. J. 1992. The structure of narrative explanation in history and biology. In History and Evolution, eds. M. H. Nitecki and D. V. Nitecki, 19-54. Albany: State University of New York Press.

Roth, P. A. 1989. How narratives explain. Social Research 56(2): 449478.

Scholl, R. 2020. Unwarranted assumptions: Claude Bernard and the growth of the vera causa standard. Studies in History and Philosophy of Science Part A 82: 120-130.

Scriven, M. 1962. Explanations, predictions, and laws. In Minnesota Studies in the Philosophy of Science, vol. 3, eds. H. Feigl and G. Maxwell, 170-230. Minneapolis: University of Minnesota Press.

Snoeck-Henkemans, F. 2003. Complex argumentation in a critical discussion. Argumentation 17: 405-419

Toulmin, S. E. 2003 [1958]. The uses of argument. Cambridge: Cambridge University Press.

Toulmin, S. E. 1961. Foresight and understanding: An enquiry into the aims of science. Bloomington: Indiana University Press.

Wagemans, J. H. M. 2016. Argumentative patterns for justifying scientific explanations. Argumentation 30(1): 97-108.

Waismann, F. 1968 [1956]. How I see philosophy. In How I See Philosophy, ed. R. Harré, 1-38. London: Palgrave Macmillan.

Walton, D. N. 2004. Abductive reasoning. Tuscaloosa, AL: The University of Alabama Press.

Williamson, T. 2007. The philosophy of philosophy. Malden MA and Oxford: Blackwell.

Wittgenstein, L. 2001 [1953]. Philosophical investigations. The German text, with a revised English translation. Malden MA and Oxford: Blackwell. 
Woods, J. preprint a. Logic naturalized. (Accessed May 30 2021) https://www.johnwoods.ca/

Woods, J. preprint b. Reorienting the logic of abduction. (Accessed May 30 2021) https://www.johnwoods.ca/

Woods, J. 2017. Reorienting the logic of abduction. In Springer handbook of model-based science, eds. L. Magnani and T. Bertolotti, 137150. Dordrecht: Springer.

$\mathrm{Yu}, \mathrm{S}$. and F. Zenker. 2018. Peirce knew why abduction isn't IBE. A scheme and critical questions for abductive argument, Argumentation 32(4): 569-587. 